\title{
A Boy With Sjogren's Syndrome and Recurrent Parotitis Who Presented With Suspicious of Allergic and Immunological Disease: Review of the Literature
}

\author{
Hatice Eke Gungor ${ }^{\mathrm{a}, \mathrm{e}}$, Funda Bastug ${ }^{\mathrm{b}}$, Humeyra Aslaner ${ }^{\mathrm{c}}$, \\ Mehmet Akif Dundarc, Yasemin Altuner Torun ${ }^{\mathrm{d}}$
}

\begin{abstract}
Recurrent parotitis (RP) is an acute, severe inflammation of one or both parotid glands which are major salivary glands in younger children. Most common causes of RP include bacterial and viral infections, juvenile RP, anatomic abnormalities and auto-immune diseases. Association of RP with allergic and immunological diseases has been rarely reported. Primary Sjogren's syndrome (pSS) is a rare auto-immune disease, particularly in childhood. Rarely, pSS may be diagnosed in men, although it predominantly affects women. Here, we reported a 4-year-old boy who presented with suspicion of allergic diseases, recurrent swelling of salivary glands, positive anti-nuclear and anti-Ro/SS-B antibodies, positive rheumatoid factor and mild hypergammaglobulinemia but not apparent sicca symptoms.
\end{abstract}

Keywords: Allergic disorder; Child; Sjogren's syndrome; Immunological disorder; Recurrent parotitis

\section{Introduction}

Recurrent parotitis (RP) is an acute, severe inflammation of one or both parotid glands, which is often associated

Manuscript accepted for publication June 26, 2014

${ }^{a}$ Division of Pediatric Allergy-Immunology, Department of Pediatrics, Kayseri Education and Research Hospital, 38010 Erkilet Kayseri, Turkey

${ }^{\mathrm{b}}$ Division of Pediatric Nephrology, Department of Pediatrics, Kayseri Education and Research Hospital, 38010 Erkilet Kayseri, Turkey

${ }^{c}$ Department of Pediatrics, Kayseri Education and Research Hospital, 38010 Erkilet Kayseri, Turkey

${ }^{\mathrm{d}}$ Division of Pediatric Hematology, Department of Pediatrics, Kayseri

Education and Research Hospital, 38010 Erkilet Kayseri, Turkey

${ }^{\mathrm{e}}$ Corresponding Author: Hatice Eke Gungor, Division of Pediatric

Allergy-Immunology, Department of Pediatrics, Kayseri Education and

Research Hospital, 38010 Erkilet Kayseri, Turkey.

Email: haticeekegungor@hotmail.com

doi: http://dx.doi.org/10.14740/ijcp156w with pain, fever and redness. The incidence is unknown, since there are only case series reported. It is more common among boys, with a peak age of onset between 3 and 6 years [1]. RP is a relatively rare entity with unclear etiology and pathogenesis. Differential diagnosis should be considered in case of RP, including infections caused by bacterial (Streptococci spp. and Staphylococcus spp.) and viral agents (paramyxovirus, Epstein-Barr virus, cytomegalovirus, human immunodeficiency virus, parvovirus), and less usually, pneumoparotid, juvenile RP or anatomic abnormalities such as calculi or tumors. In addition, auto-immune diseases such as Sjogren's syndrome (SS) or sarcoidosis can also cause RP, but these are extremely rare causes. However, one should maintain high level of suspicion in case of a child presenting with RP, especially in bilateral involvement. Association of $\mathrm{RP}$ with allergic and immunological diseases has been rarely reported [1]. Associations of recurrent parotid with immune deficiencies such as isolated immunoglobulin $\mathrm{G}_{3}\left(\mathrm{IgG}_{3}\right)$ deficiency, immunoglobulin A ( $\operatorname{Ig} \mathrm{A})$ deficiency, hypogammaglobulinemia, immunoglobulin M (IgM) deficiency or Xlinked hypogammaglobulinemia and allergic diseases such as atopic dermatitis, blepharitis or hay fever have also been reported [2-8] (Table 1). In this manuscript, we reported a 4 -year-old boy presented with multiple episodes of painful swelling in both parotid glands over a 2 -year period and suspicion of allergic disease.

\section{Case Report}

A 4-year-old boy presented to our clinic with multiple episodes of painful swelling in both parotid glands over 2 years. The patient received prior therapies with diagnosis of mumps, parotid cyst or sialolithiasis; however, he did not respond to these therapies; thus, the patient was referred to allergy-immunology outpatient clinic with suspicion of allergic or immunological disease. In the history, there were episodes of severe arthralgia, local edema, fatigue and fever, which resolved within $48 \mathrm{~h}$. There was no xerophthalmia or xerostomia. In his family history, there was no auto-immune disease or rheumatic disorder. On physical examination, there were swollen bilateral parotid glands with local 
Table 1. Previous Cases of RP Associated With Allergic and Immunological Disease

\begin{tabular}{|c|c|c|c|}
\hline Autors & Age (year) & Sex & Disorder \\
\hline Friis et al [4] & 13 & $\mathrm{~F}$ & $\begin{array}{l}\text { Atopicdermatitis } \\
\text { Hay fever } \\
\text { IgA deficiency } \\
\text { Gluten enteropathy } \\
\text { High titers of ANA } \\
\text { Blepharitis }\end{array}$ \\
\hline Conley et al [2] & $\begin{array}{l}5 \\
2\end{array}$ & $\begin{array}{l}\mathrm{M} \\
\mathrm{F}\end{array}$ & $\begin{array}{l}\text { CVID } \\
\text { CVID }\end{array}$ \\
\hline Steuer et al [5] & 24 & M & $\begin{array}{l}\text { Primary SS } \\
\text { Ulcerative colitis } \\
\text { sIgA deficiency }\end{array}$ \\
\hline Marsman et al [3] & 5 & $\mathrm{~F}$ & Isolated $\mathrm{IgG}_{3}$ sub-class deficiency \\
\hline Munro et al [6] & 12 & M & $\begin{array}{l}\text { Two brothers with X-linked } \\
\text { agammaglobulinemia }\end{array}$ \\
\hline Shkalim et al [7] & 9 & $\mathrm{~F}$ & sIgA deficiency \\
\hline Fazekas et al [8] & $\begin{array}{l}\text { Five patients } \\
7 \text { months } \\
1 \\
3 \\
12 \\
13\end{array}$ & & $\begin{array}{l}\text { sIgA deficiency } \\
\text { sIgA deficiency } \\
\text { sIgA deficiency } \\
\text { sIgA deficiency } \\
\text { sIgA deficiency }\end{array}$ \\
\hline
\end{tabular}

slgA: selective immunoglobulin A; CVID: common variable immunodeficiency; pSS: primary Sjogren's syndrome.

tenderness, erythema at overlying skin, bilateral cervical lymphadenopathy and oral aphthous stomatitis. No other pathological finding was detected on physical examination. Laboratory evaluations revealed the following findings: white blood cell count, $10,900 / \mathrm{mm}^{3}$ with neutrophilia; serum amylase, $282 \mathrm{U} / \mathrm{L}$ (normal range: $30-100 \mathrm{U} / \mathrm{L}$ ), elevated acute phase reactants (erythrocyte sedimentation rate, 70 $\mathrm{mm} / \mathrm{h}$ (normal range: 0 - 20); C-reactive protein, $27.4 \mathrm{mg} / \mathrm{L}$ (normal range: 0 - 5), positive antinuclear antibody (ANA), positive Sjogren's syndrome B antigen (SS-B) auto-antibodies, positive rheumatoid factor (RF) and mild hypergammaglobulinemia. Anti-double stranded DNA, anti-Smith, antiSjogren's syndrome A antigen (SS-A) and anti-phospholipid antibodies and direct Coombs test were negative. In the immune assays, findings were as follows: $\operatorname{IgG} 1,040 \mathrm{mg} / \mathrm{dL}$ (normal range: 350 - 1,020); IgM $117 \mathrm{mg} / \mathrm{dL}$ (normal range: 30 - 265); and $\operatorname{IgA} 115 \mathrm{mg} / \mathrm{dL}$ (normal range: 17 - 318). Lymphocyte subsets were within normal limits. Skin prick tests were negative. Parotid gland sonography demonstrated multifocal hypoechoic areas within parenchyma of swollen glands (Fig. 1). Parents declined sialography or biopsy. It failed to perform Shimer test, as the patient did not show adherence. Ibuprofen, hydroxychloroquine and artificial tears were prescribed to the patient. No recurrence of parotitis was observed after therapy.

\section{Discussion}

$\mathrm{RP}$ at childhood is a rare condition with unclear etiology; however, it can be associated with congenital malformations, viral or bacterial infections, hypersensitivity, immunodeficiency, auto-immune and allergic diseases or systemic diseases such as SS in some cases. In a case report, Conley et al defined two children with common variable immunodeficiency (CVID) who had episodes of RP, including a 5-yearold boy and a 2-year-old girl [2]. In another study, a 5-yearold girl with isolated $\mathrm{IgG}_{3}$ deficiency and RP was described [3]. Authors reported that frequency of parotitis episodes was decreased by prophylactic treatment with co-trimoxa- 


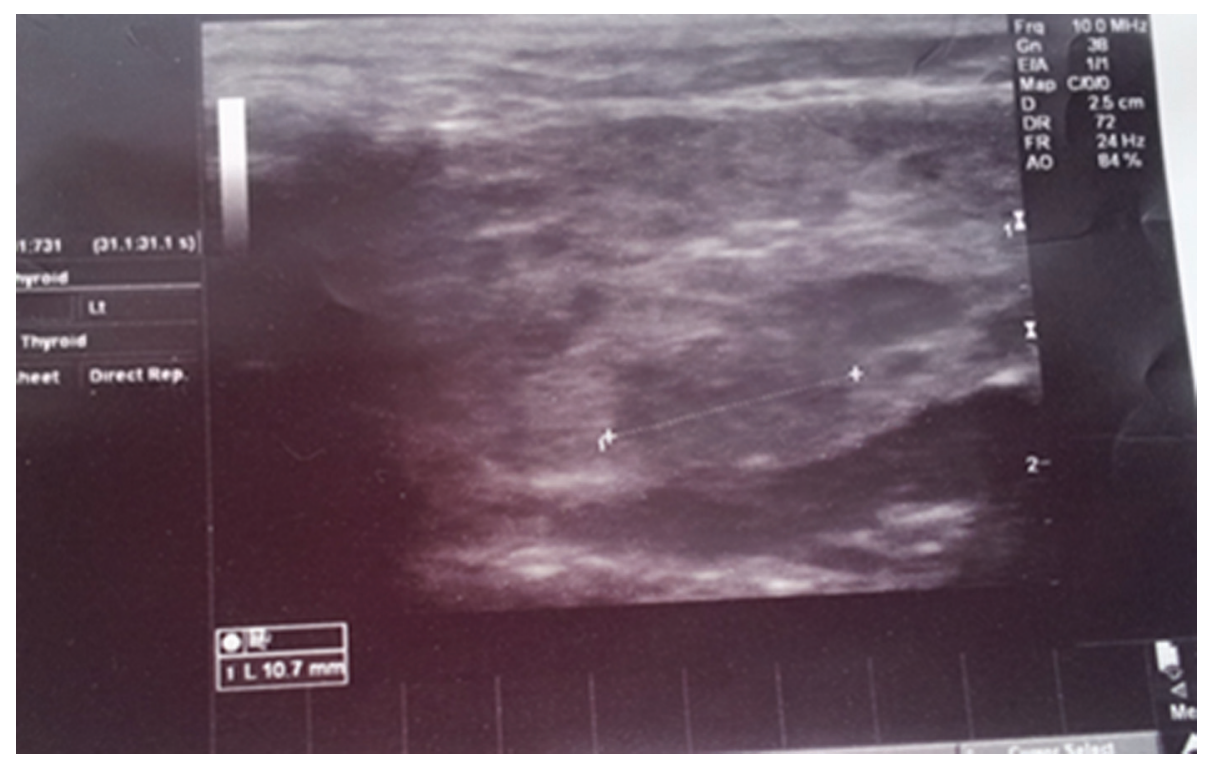

Figure 1. Ultrasonographic image of the parotid gland revealed an increase in the size of the parotid glands and multiple hypoechoic focal areas.

zole. In a study by Friis et al, a 13-year-old girl was reported, who had allergic disorders such as atopic dermatitis, blepharitis, hay fever and IgA deficiency, and gluten enteropathy and elevated ANA titers in association with RP [4]. In a case report by Steuer et al, a 24-year-old man was defined, who had SS, parotitis, ulcerative colitis and IgA deficiency. Munro et al declared three adolescent girls who had RP for long and newly diagnosed pSS. In one of these cases, authors reported family history of X-linked agammaglobulinemia in two siblings [6]. Shkalim et al reported a child who had RP and isolated IgA deficiency but not auto-immune or allergic disease. Individuals with IgA deficiency may occasionally present with sinopulmonary infections, atopy, gastrointestinal diseases or auto-immune disorders; however, majority of these individuals remain healthy. IgA is the primary immunoglobulin secreted into mucosal surfaces and saliva, including respiratory and gastrointestinal tracts. The finding of higher prevalence of IgA deficiency among children with RP suggests that lack of IgA in the parotid glands may be associated with inability of complete clearance of inflammatory stimuli in the glands $[7,8]$. In our case, no allergic or immunological disorder was detected; rather, a mild hypergammaglobulinemia was observed. The patient was diagnosed as pSS by positive ANA, positive SS-B auto-antibodies, positive RF and multifocal hypoechoic areas within parenchyma of enlarged parotid glands on sonography.

SS is a chronic auto-immune disorder characterized by xerosis of the exocrine glands, lacrimal and salivary glands in particular. It can be primary or secondary in association with other auto-immune diseases such as rheumatoid arthritis or systemic lupus erythematosus or scleroderma. Primary $\mathrm{SS}$ is more common in adults, especially in middle-aged women, but it is rarely seen in children with female predominance and peak incidence at 10 years of age. It is a rare autoimmune disease at childhood, mainly affecting girls (77\%) and those aged around 10 years of age [9]. In 1994, in a national survey from Japan, 61 cases recorded (nine in boys and 52 girls). The cases were primary SS in $70 \%$ (42 cases) and secondary SS in 30\% (19 cases) of the cases [10]. Our patient was a 4-year-old boy.

The diagnosis of SS based on presence of four of six following criteria [11]: ocular symptoms, oral symptoms, evidence of keratoconjunctivitissicca, focal sialoadenitis by minor salivary gland biopsy, instrumental evidence of salivary gland involvement and presence of SS-A or SS-B auto-antibodies. However, our patient did not fulfill American-European Consensus Group classification criteria, but clinical and laboratory signs were appropriate with pSS. In the literature, it has been reported that anti-SS-A antibodies are positive in more than $70 \%$ while anti-La/SS-B antibodies were positive in more than $30 \%$ of the patients with SS [12]. In adult patients, there is a strong correlation between SS and anti-SS-A and anti-SS-B antibodies. In a study from The Netherlands, systemic antibodies were commonly detected in patients with SS including anti-SS-A and/or anti-SS-B $(80 \%)$, IgM-RF (68\%) and ANA (77\%) [13]. Presence of systemic auto-antibodies is often associated with presence of hypergammaglobulinemia. According to literature, in pSS, $29 \%$ of the cases can be seronegative for SS-A (anti-Ro) antibodies, while approximately $33 \%$ can be seronegative for SS-B (anti-La) antibodies in pSS [14]. Our case had positive ANA, RF and anti-La/SS-B antibodies.

In previous studies, it was shown that sonography could ensure significant diagnostic knowledge [15]. Hypoechoic 
areas within salivary gland have been reported on sonography in patients with pSS; however, composition of these hypoechoic areas is still unknown. In our case, hypoechoic areas were also detected on sonography. Historically, the management varies from conservative measures to radiotherapy or total parotidectomy. It is well-known that it has benign natural course; therefore, conservative approach is recommended in most cases.

Clinicians should be careful in cases presented with RP for auto-immune diseases, particularly in those with bilateral involvement. However, this case was reported to emphasize that allergic and immunological disorders should be kept in mind in such cases, although rare.

\section{Conflict of Interest}

The author(s) declared no potential conflicts of interest with respect to the research, authorship, and/or publication of this article.

\section{Financial Support}

There is no source of financial support.

\section{References}

1. Leerdam CM, Martin HC, Isaacs D. Recurrent parotitis of childhood. J Paediatr Child Health. 2005;41(12):631634.

2. Conley ME, Park CL, Douglas SD. Childhood common variable immunodeficiency with autoimmune disease. J Pediatr. 1986;108(6):915-922.

3. Marsman WA, Sukhai RN. Recurrent parotitis and isolated IgG3 subclass deficiency. Eur J Pediatr. 1999;158(8):684.

4. Friis B, Karup Pedersen F, Schiodt M, Wiik A, Hoj L, Andersen V. Immunological studies in two children with recurrent parotitis. Acta Paediatr Scand. 1983;72(2):265268.
5. Steuer A, McCrea DJ, Colaco CB. Primary Sjogren's syndrome, ulcerative colitis and selective IgA deficiency. Postgrad Med J. 1996;72(850):499-500.

6. Munro J, Allen R. Recurrent parotitis and Sjogren's syndrome. J Paediatr Child Health. 2003;39(2):158-159; author reply 159.

7. Shkalim V, Monselise Y, Mosseri R, Finkelstein Y, Garty BZ. Recurrent parotitis in selective IgA deficiency. Pediatr Allergy Immunol. 2004;15(3):281-283.

8. Fazekas T, Wiesbauer P, Schroth B, Potschger U, Gadner H, Heitger A. Selective IgA deficiency in children with recurrent parotitis of childhood. Pediatr Infect Dis J. 2005;24(5):461-462.

9. Singer NG, Tomanova-Soltys I, Lowe R. Sjogren's syndrome in childhood. Curr Rheumatol Rep. 2008;10(2):147-155.

10. Tomiita M, Saito K, Kohno Y, Shimojo N, Fujikawa S, Niimi H. The clinical features of Sjogren's syndrome in Japanese children. Acta Paediatr Jpn. 1997;39(2):268272.

11. Vitali C, Bombardieri S, Jonsson R, Moutsopoulos HM, Alexander EL, Carsons SE, Daniels TE, et al. Classification criteria for Sjogren's syndrome: a revised version of the European criteria proposed by the American-European Consensus Group. Ann Rheum Dis. 2002;61(6):554558.

12. Saad Magalhaes C, de Souza Medeiros PB, Oliveira-Sato J, Custodio-Domingues MA. Clinical presentation and salivary gland histopathology of paediatric primary Sjogren's syndrome. Clin Exp Rheumatol. 2011;29(3):589593.

13. ter Borg EJ, Risselada AP, Kelder JC. Relation of systemic autoantibodies to the number of extraglandular manifestations in primary Sjogren's Syndrome: a retrospective analysis of 65 patients in the Netherlands. Semin Arthritis Rheum. 2011;40(6):547-551.

14. Hammi AR, Al-Hashimi IH, Nunn ME, Zipp M. Assessment of SS-A and SS-B in parotid saliva of patients with Sjogren's syndrome. J Oral Pathol Med. 2005;34(4):198203.

15. Daniels TE. Do we need new diagnostic criteria for Sjogren's syndrome? Presse Med. 2012;41(9 Pt 2):e441449 . 